\title{
Atrial fibrillation prophylaxis and esophageal resection - our experience
}

V. Karadza, N. Hodoba, J. Spicek Macan, D Stancic-Rokotov, N. Kolaric, S. Sakan University Hospital Centre Zagreb, Clinic for Thoracic Surgery, Zagreb, Croatia

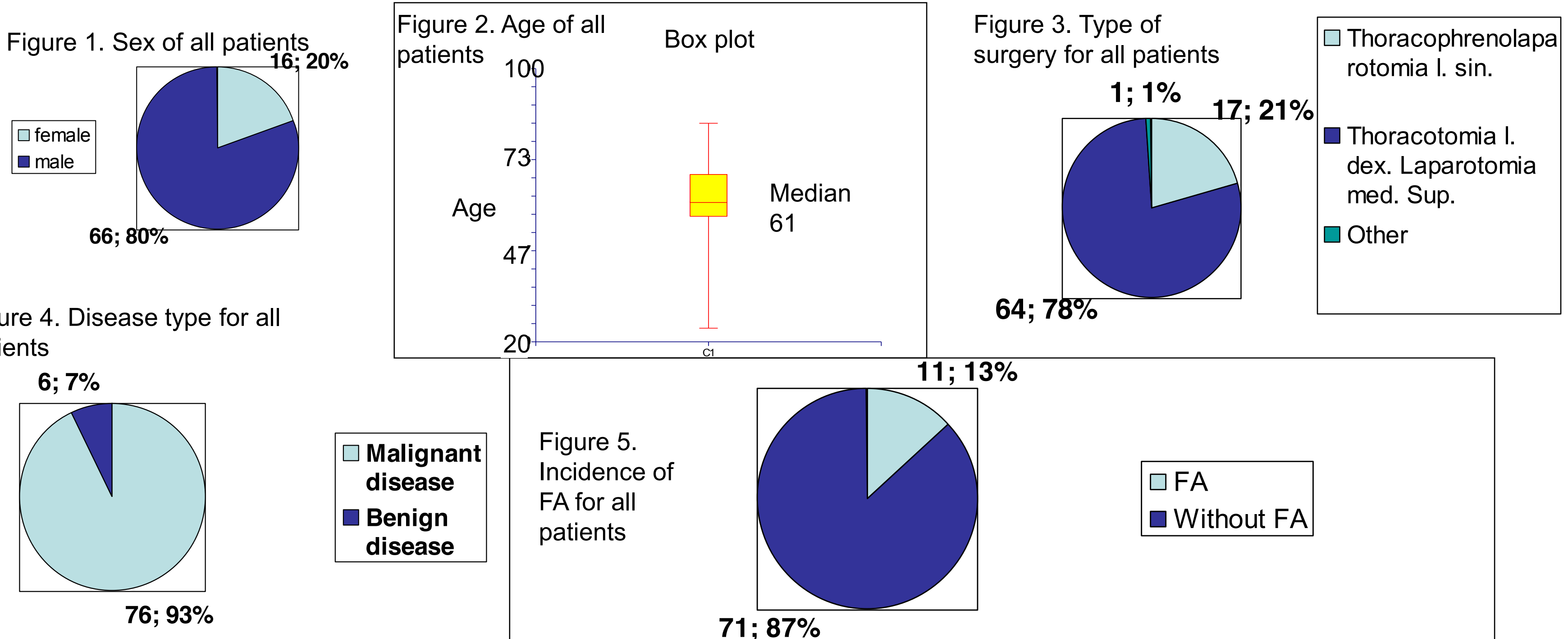

Figure 6. All groups of patients with naming of further analyzed

$\square$ FA $\square$ Without FA groups (A, B)

\section{Continuing preoperative antiarrhytmics}

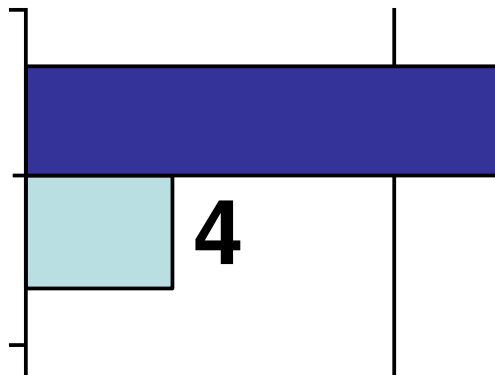

13
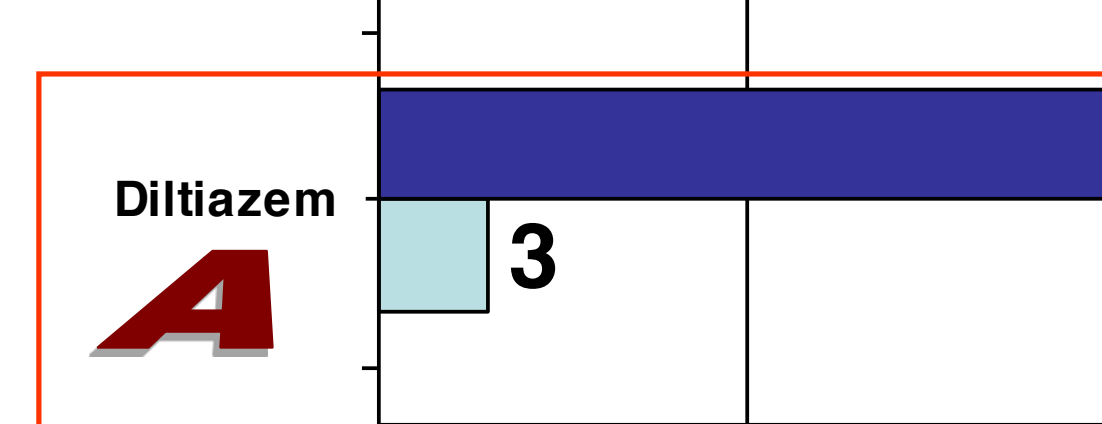

20

Without prophylaxis
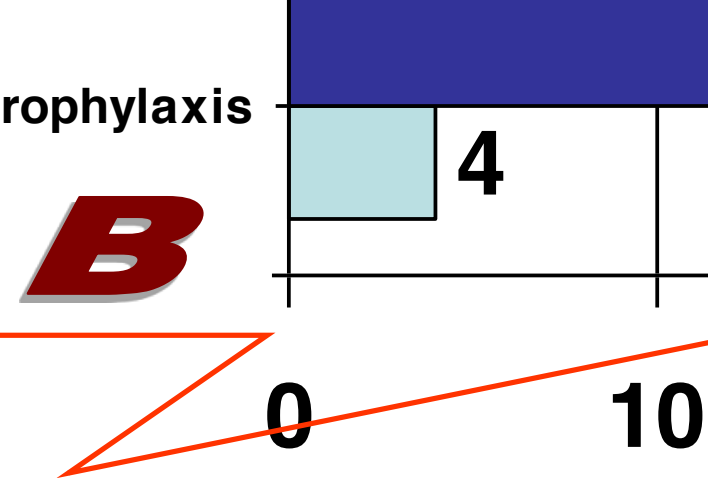

10

20

Statistically analyzed groups A and B (in red)

The Fisher exact test statistic value is 0.690862 . The result is not significant at $p<.05$.

The chi-square statistic is 0.1916 . The $p$-value is .661598 . This result is not significant at $p<.05$.

\begin{tabular}{|c|c|c|}
\hline & \multicolumn{2}{|c|}{$\begin{array}{l}\text { Table 1. Number of FA } \\
\text { cases / groups A and B }\end{array}$} \\
\hline & $\begin{array}{l}\text { No } \\
\text { prophylaxis } \\
\text { (GroupB) }\end{array}$ & $\begin{array}{l}\text { Diltiazem } \\
\text { (Group A) }\end{array}$ \\
\hline$<=55$ years & 2 & \\
\hline $\begin{array}{l}\text { Age } \\
\qquad>=56 \text { years }\end{array}$ & 2 & 3 \\
\hline
\end{tabular}

For age group $>=56$ years $(A, B)$ :

The Fisher exact test statistic value is 0.642831 . The result is not significant at $p<.05$
Place: Clinics for Thoracic Surgery, University Hospital Centre Zagreb

Time: November 2012. - May 2015. Number of all patients undergone oesophageal resection: 82

ASA III 43 patients - 10 FA and ASA II 38 patients - 1 FA

Comorbidity: HA 28, DM 8, AP 6 patients (other less then 5 )
Number of patients

40

Number of patients in groups A and B: 65 The Highest Noticed Ventricular Answer Group A :140, median 130 (110-140) Group B : 180median 159 (130-180)

Figure 7. Groups A and B by age
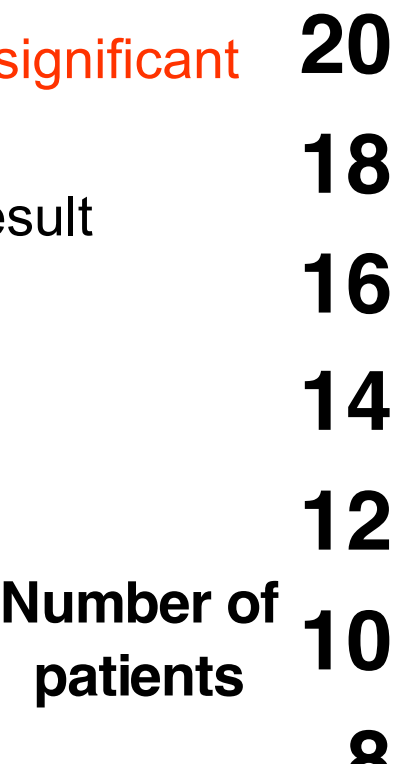

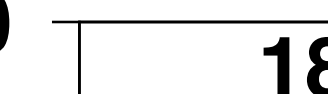

References: Frendel $\mathrm{G}$ et al. 2014 AATS guidelines for prevention and management of perioperative atria

fibrillation and flutter for thoracic surgery procedures. J Thorac Cardiovasc Surg. 2014;148.3:153-193 